ORIGINAL ARTICLE

\title{
Head injuries in Leeds: changes in epidemiology and survival over 12 years
}

\author{
M D Wittenberg, J P Sloan, I F Barlow
}

Emerg Med J 2004;21:429-432. doi: 10.1136/emj.2003.006775

See end of article for authors' affiliations

......................

Correspondence to: Dr M Wittenberg, c/o Mr J P Sloan, Accident and Emergency Department The General Infirmary at Leeds, Great George Street, Leeds LS1 3EX, UK; doctor@wittenberg.org.uk

Accepted for publication 17 November 2003

\begin{abstract}
Objectives: To map the pattern of survival and epidemiology of patients admitted to accident and emergency, at a regional neurosciences unit with an isolated head injury, over a 12 year period.

Methods: The TARN database of a regional neuroscience referral centre was analysed to identify patients who where admitted after a significant, isolated head injury between January 1990 and December 2001. Demographic data about the patient and nature and cause of the injury were extracted and survival was mapped over the time period. Statistical analysis was performed to identify change in survival.

Results: There were 810 eligible patients. The most common cause of injury was road traffic accident $(47 \%)$ with an average of $42.6 \%$ patients transferred from other hospitals. The most common disposal of patients was to an intensive care unit (35\%). There was an overall increase in the number of patients but survival did not increase over the time period. Mean survival was $81.8 \%$ and overall survival decreased from $95.0 \%$ in 1990 to $81.6 \%$ in 2001 , although this did not represent significant change $(p=0.990)$.

Conclusions: Short term survival after significant head injury has not changed significantly over the 12 year period studied. No subset of patients is having a disproportionate effect on survival but in patients aged over 75, survival increased significantly. Further multicentre work is indicated to map a more accurate clinical picture of head injury survival.
\end{abstract}

$\mathrm{H}$ ead injury is a major health problem worldwide. Indeed, it is the single most common cause of death in those under the age of 40 and is also the most common cause of death and disability in young people. ${ }^{1}$ The frequency of head injury has increased recently, in large measure because of our technologically advanced society, and the sheer volume of milder injuries (Glasgow coma scale (GCS) of 13 to 15) poses a logistical problem for accident and emergency (A\&E) departments. Some one million patients present to British hospitals each year with a head injury ${ }^{2}$ but it is estimated that only $1 \%$ of these patients are actually transferred to neurosurgical units. ${ }^{3}$ Therefore the large majority of care for these patients is undertaken by nonspecialists, particularly those in A\&E.

Of the one million patients attending A\&E with head injuries annually in the UK, classification can be made according to severity: $80 \%$ are mild (GCS 13 to 15 ); $10 \%$ are moderate (GCS 9 to 12 ), and $10 \%$ are severe (GCS 3 to 8 ). ${ }^{4}$ However, this may be changing as a result of hospital managed care practices. Observational data from the USA suggest that the proportions may be closer to $60 \%, 20 \%$, and $20 \%$ for mild, moderate, and severe, respectively. ${ }^{5}$ Nevertheless, severe head injury is a major factor in more than $50 \%$ of trauma related deaths and account for a significant proportion of the workload within an A\&E department. ${ }^{4}$

The management of head injuries has changed within the past 10 to 15 years, particularly with the publication of the Royal College of Surgeons of England (RCSE) guidelines in 1986 and 1999. These were designed to reduce mortality and morbidity among this set of patients, particularly those with moderate and severe injuries $(\mathrm{GCS} \leqslant 9)$. However, there are few data published reporting the picture of contemporary practice and the pattern of survival among head injured patients admitted to A\&E. Patients with significant head injuries are at significant risk of hypotension, hypoxaemia, and brain swelling and if these are not treated, they increase the risk of death.

The General Infirmary at Leeds (LGI) is a regional referral centre for neurosciences and so the A\&E department acts as a major reception point for patients with a head injury. An important role of the A\&E department is to determine which patients could either go home, be admitted for less than 48 hours within A\&E, or be transferred for neurosurgery, ICU, or neurosciences. They also have a role in the initial management of the patient. Currently, treatment of head injured patients is guided by clinical assessments and protocols based on the GCS. ${ }^{6}$ This is accompanied by resuscitation, stabilisation of the cervical spine, and ensuring adequate ventilation and perfusion.

In Leeds, a comprehensive computerised database is kept of patients admitted to the A\&E department at the LGI. This is now over 10 years old and permits analysis, particularly of subsets of patients. It has previously been shown that changes in trauma care in Leeds have resulted in significantly fewer deaths from major trauma in 1992/93 compared with 1988/89. ${ }^{7}$ In addition, an audit of the same database showed that survival from spinal injuries also increased significantly over the decade to 2001 (personal communication).

\section{AIM}

We set out to map the characteristics of the subset of patients admitted to the LGI A\&E department with an isolated head injury between January 1990 and December 2001. Within this, we postulated that, in line with improvements in survival in other studies, survival of head injured patients would increase significantly over this time period.

\section{METHODS}

A single trauma clerk (IFB) has been responsible for compiling and maintaining the A\&E database in Leeds. This raw dataset consists of every case matching the TARN (Trauma Audit and Research Network) patient selection data. The TARN ${ }^{8}$ inclusion criteria are strictly adhered to, ensuring that patient selection is consistent:

- A patient must be admitted to an HDU/ICU bed after a traumatic method of injury. Or, 
- A patient must remain an inpatient for 72 hours or more, because of one or more injuries. Or,

- A patient has died in hospital after one or more injuries (this includes patients who died in the resuscitation room after serious injury).

There are some special cases in addition to this. Isolated, single, simple fractures that are treated conservatively are ignored and so too are elderly patients who have suffered a femoral fracture. However, tertiary referrals that fulfil one or more of the above criteria are included.

All patients within the database were eligible for the study. Firstly, selection was based on a specific date range (1 January 1990 to 31 December 2001). Within this, patients who had an isolated, significant head injury were located. This was done by evaluating each patient's AIS (abbreviated injury score) code and AIS severity score.

For each patient, demographic data were extracted from the database. The discharge status was used to assess survival: this was simply a binary outcome whereby the patient left hospital alive or dead and so no account of long term survival was made. From this, overall patient survival over the time period could be evaluated, along with an analysis of method of injury and patient outcome. Statistical analysis used a one way analysis of variance over time.

Table 1 Epidemiology of 810 patients admitted to LGI A\&E from 1990 to 2001

\begin{tabular}{lll}
\hline & Number & Percentage \\
\hline Total patients & 810 & \\
Total females & 215 & 26.5 \\
Total males & 595 & 73.5 \\
Age distribution (y) & & \\
$0-9$ & 140 & 17.3 \\
$10-19$ & 129 & 15.9 \\
$20-29$ & 121 & 14.9 \\
$30-39$ & 95 & 11.7 \\
$40-49$ & 100 & 12.3 \\
$50-59$ & 88 & 10.9 \\
$60-69$ & 51 & 6.3 \\
$70-79$ & 47 & 5.8 \\
$80-89$ & 93 & 11.5 \\
$90-99$ & 2 & 0.2 \\
\hline
\end{tabular}

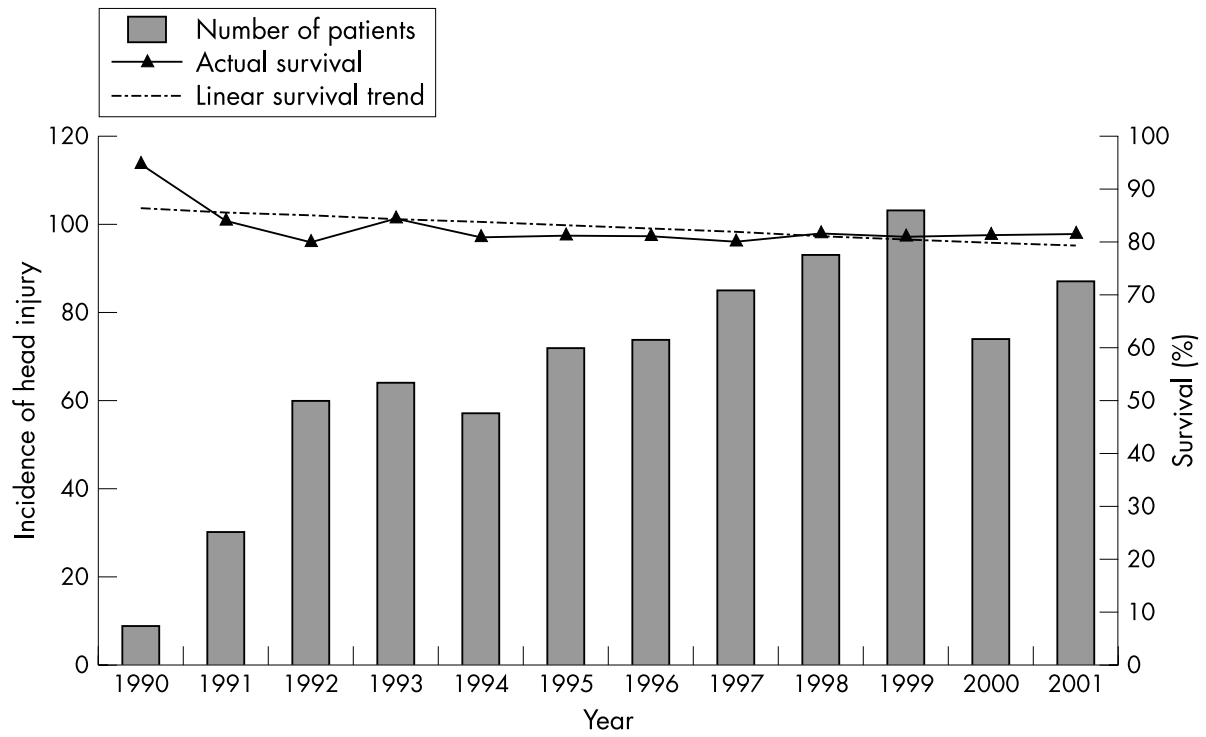

Figure 1 Bar graph showing number of patients with head injury and line graph showing survival percentage per year. Bars show number of patients; triangles show actual survival; dashed line shows linear survival trend.
There were 810 eligible patients. As table 1 shows, the ratio of males to females is approximately 3:1 and the majority of patients fell within the 21 to 45 year old age bracket. The median age was 31.7 years while the mean was 34.1 years. However, the most populous age group is that of children aged 9 years and under.

Figure 1 shows that actual patient survival decreased overall from 1990 to 2001 from $95.0 \%$ to $81.58 \%$. There was also a steady increase in the numbers of patients being admitted to A\&E with a head injury, but with a decrease between 1999 to 2000. The peak incidence of patients was in 1999, with the smallest numbers attending in 1990. The dashed trend line does not show an upward trend in survival. The highest survival was in 1990 but this also correlated with the lowest number of patients. The mean survival over the 12 years was $82.9 \%$ and the mean number of patients was 67 . To ascertain any statistical difference in patient survival over the time period studied, survival per year was compared using a one way analysis of variance. This is shown in table 2 and demonstrates a p value of 0.990 over 12 years.

The methods of injury over the time period are shown in figure 2 and overall, the most common method is that of falls $(47 \%)$. However, there are slightly more falls under 2 metres (24\%) than falls over 2 metres (21\%). RTAs form the biggest individual group over the whole period $(25 \%)$ and within this, the largest proportion (66\%) were pedestrians with drivers and front seat passengers being the next most common positions ( $14 \%$ and $9 \%$ respectively). Within the time period studied, new legislation made rear seatbelts compulsory. However, there were only nine patients $(1.1 \%$ of total population) who were recorded as being rear seat passengers, making significant analysis impossible. The proportion of head injuries caused by RTAs does not decrease significantly over the 12 years. Equally, the proportion of assaults remains similar over the time period, with the average being $16 \%$. Sporting injuries decrease over the years, and the number of injuries from non-accidental injury $(2 \%$ overall) is sporadic with there being none from 1990 to 1993 or in 2000. Other, non-classified causes of head injury form a small group in all years studied $(6 \%)$.

The pattern of patient outcome has changed over the time period studied. As the LGI is a tertiary referral centre, it can be expected that a high proportion of patients will have been transferred from other hospitals. In fact, an average of $42.6 \%$ of patients over the time period were

(enionine.com 
Table 2 One way analysis of variance of survival over 12 years

\begin{tabular}{llllll}
\hline & Sum of squares & df & Mean square & $\boldsymbol{F}$ & Significance (p value) \\
\hline Between groups & 1114.572 & 11 & 101.325 & 0.269 & 0.990 \\
Within groups & 45574.355 & 121 & 376.648 & & \\
Total & 46688.927 & 132 & & & \\
\hline
\end{tabular}

transferred in. Table 3 details where the patient went to after their discharge from A\&E. The highest proportion of patients went to ICU to be cared for directly by the neurologists and neurosurgeons (35\%). A large proportion was admitted to the ward $(27 \%)$ but it is also notable that $24 \%$ patients went home.

\section{DISCUSSION}

The epidemiology of the patients in the LGI dataset seems to correlate well with the rest of the literature. The ratio of 1:3 females to males agrees with the European Brain Injury Consortium report. ${ }^{9}$ The major causes of injury in this study is a pattern well reported in the literature, although in studies where the incidence of gun carrying is high, gunshot wounds are normally the primary cause of injury. ${ }^{3}$ The decrease in injuries caused by sport may reflect that safety improvements made in dangerous sports such as boxing and rugby, while the sporadic proportion of injuries caused by NAI may well be as a result of reporting discrepancies.

It is clear that survival did not increase over the time period studied, and furthermore, a p value of 0.990 shows that there is little change over the 12 years. Subsets were created to ascertain whether any particular patient group was having a disproportionate effect on survival. When sorted by age, survival decreased in the under 16 year olds, and in the 21 to 45 year olds. However, in the over 75 age group, survival increased significantly from just over $0 \%$ to $21 \%$ but this group only accounts for $5.7 \%$ of the total population. Transferred patients were also separated to establish whether transportation was having an adverse effect on survival. In fact, survival in transferred patients remained comparatively constant throughout the years at just over $80 \%$ whereas in non-transferred patients, survival decreased in a pattern similar to the overall patient group. This may demonstrate

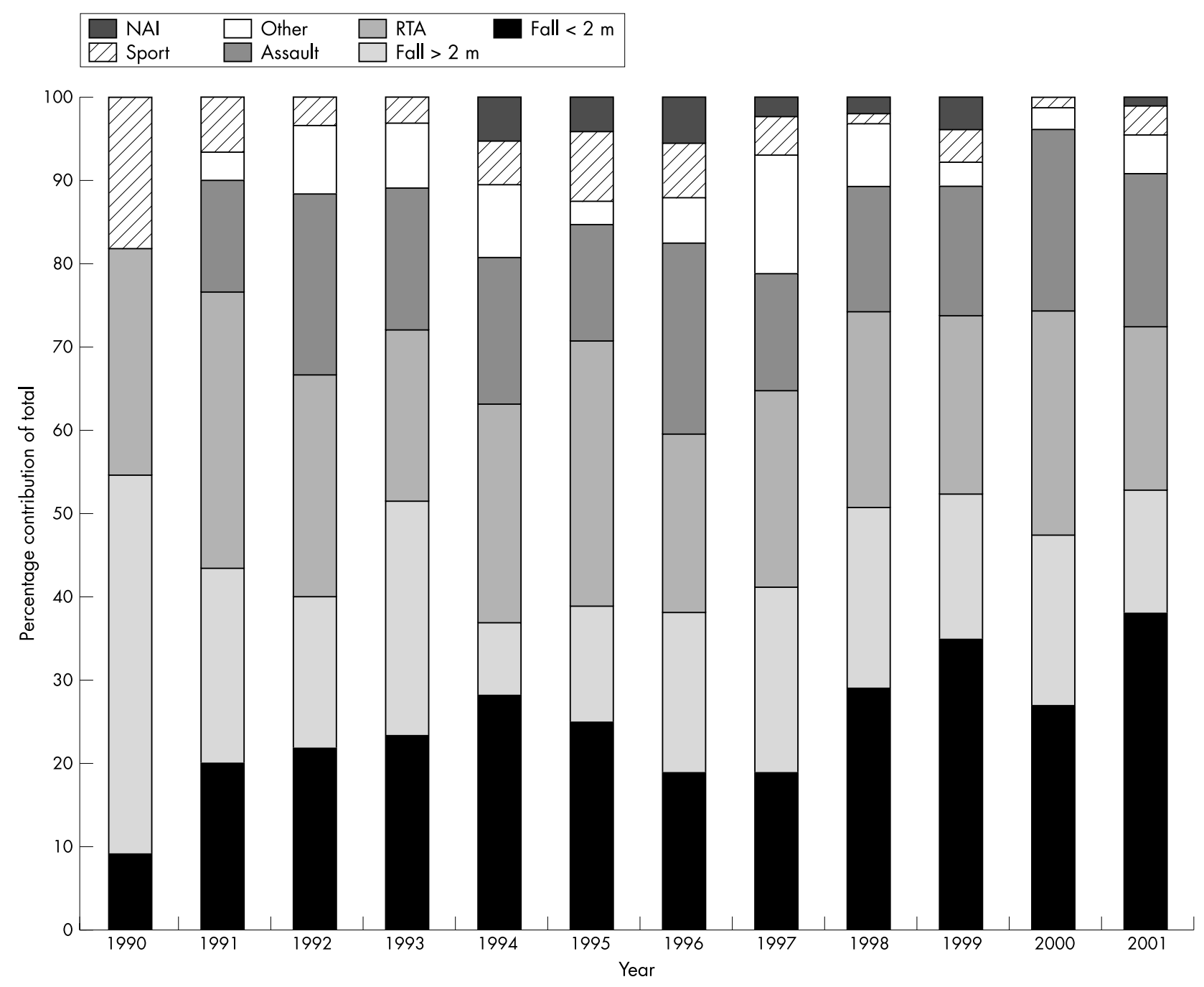

Figure 2 Methods of injury over the time period studied. 
Table 3 Destination after discharge from A\&E

\begin{tabular}{ll}
\hline Immediate disposal & Incidence (\%) \\
\hline Intensive care unit & 35 \\
Ward & 27 \\
Home & 24 \\
Theatre & 8 \\
CT/radiography & 3 \\
High dependency unit & 1 \\
Transfer & 1 \\
Mortuary & 1 \\
\hline
\end{tabular}

that the population is inevitably skewed as the neurosciences centre is not able to accept all patients from the region. Constraints on bed space may mean that some of the survivors remain in non-specialist units, and that conversely, the worst injuries (for example, GCS 3 to 8 ) will not be accepted for transfer because of the adverse effects of movement, barometric pressure changes, and temperature changes. ${ }^{10}$

The Royal College of Surgeons of England report in 1986 recommended the provision of a 24 hour computer tomography (CT) service for every general hospital with a major A\&E service. ${ }^{11}$ However, few hospitals provided this service at the time, requiring transfer to a regional neurosurgical unit. During the early 1990s, proposals from neurosurgeons and A\&E specialists led to more general hospitals acquiring CT scanners, and having them manned over 24 hours. However, the Society of British Neurological Surgeons identified the potential disadvantage of inexpert interpretation of scans in smaller district general hospitals. ${ }^{12}$ The 1999 Galasko report recommended that the part of the care of head injured patients undertaken by general or orthopaedic surgeons be transferred to A\&E and neurosciences department. ${ }^{13}$ Despite these recommendations, there has been no demonstrable major change in practice.

In comparison, pertinent data are published from Bangkok where head injured patients in 1996 where compared with those from 1985 to $1986 .{ }^{14}$ The authors found that the number of patients with head injury doubled over time but there was a trend towards less severe injury, explained by the increased use of motorcycle helmets. There was also a significant increase in mortality but the reasons for this are unknown. A larger study from Geneva reports on an overall decrease in mortality in children hospitalised from 1969 to 1991. ${ }^{15}$ There was both a significant decrease in fatalities before admission and overall mortality, which the authors attribute to improvements in decision making and management. An Edinburgh group performed three one-year surveys of head injury management spanning a nine year period. ${ }^{16}$ They note a general decrease in severity of injury and admission rates that they attribute to the introduction of guidelines for admission and seat belt legislation. We have not looked at the quality of survival and it is possible that this may have increased over the time period studied, whereby better rehabilitation to normal living has been more effective. Morbidity and functional outcome, especially in terms of cognitive function, may represent a better reflection of the secondary prevention strategies used in the early management of trauma patients.

Advances in A\&E care, imaging, and the reorganisation of the way head injury patients are treated have led to reductions in disability. However, this is a difficult patient group to treat and developments in treatment protocol will not necessarily lead to an overall increase in survival. Over 12 years, management in A\&E departments may have changed suggesting that there should be a better outcome for patients. However, this is not certain for head injuries in Leeds in particular, but Burdett-Smith et al found that the relative risk of dying from major trauma in 1992-3 compared with 1988-9 was 0.68 (95\% CI). ${ }^{7}$ Conversely, neurosurgical services and intensive care units are being pressed to take sicker patients. This may well hide a better outcome that we can demonstrate.

To see this work in context, it will be necessary to conduct similar evaluations in other centres, and to conduct the work over a longer time period. In addition, further work could be conducted examining the time period from injury to A\&E admission over 10 years and time from resuscitation to haematoma evacuation. To examine the reasons for why mortality has not fallen, the GCS on arrival in A\&E could be measured along with regular follow up over a longer period. None the less, of all major trauma, head injuries may be the group that presents the most challenge in terms of improved survival.

\section{ACKNOWLEDGEMENTS}

Many thanks to Wendy Parsons for her statistical advice.

\section{CONTRIBUTORS}

MDW analysed the dataset; JPS had the original idea for the study; MDW and JPS wrote the paper; IFB collated the database and extracted the dataset.

\section{Authors' affiliations}

M D Wittenberg, J P Sloan, I F Barlow, Accident and Emergency Department, The General Infirmary at Leeds, Leeds, UK

Funding: none.

Conflicts of interest: none declared.

\section{REFERENCES}

1 Ghajar J. Traumatic brain injury. Lancet 2000;356:923-9.

2 Turner K, Jones A, Handa A. Emergency management of head injuries. Student BMJ 2000;8:140-2.

3 Currie $\mathbf{D}$. The management of head injuries. A practical guide for the emergency room. 2nd edn. Oxford: Oxford University Press, 2000.

4 Flannery T, Buxton N. Modern management of head injuries. J R Coll Surg Edinb 2001;46:150-3.

5 Cooper PR, Golfinos JG, eds. Head injury. 4th edn. New York: McGraw-Hill, 1998.

6 Scottish Intercollegiate Guidelines Network. Early management of head injury. Edinburgh: Royal College of Physicians of Edinburgh, 2000.

7 Burdett-Smith P, Airey M, Franks A. Improvements in trauma survival in Leeds. Injury 1995;26:455-8.

8 Trauma Audit and Research Network. http://www.tarn.ac.uk (accessed 20 Jun 2002).

9 Murray GD, Teasdale GM, Braakman R. The European Brain Injury Consortium survey of head injuries. Acta Neurochir 1999;141:223-6.

10 Intensive Care Society. Guidelines for the transport of the critically ill adult. London: Intensive Care Society, 1997.

11 The Royal College of Surgeons of England. Report of the Working Party on Head Injuries. London: The Royal College of Surgeons of England, 1986.

12 Bartlett J, Kett-White R, Mendelow AD, et al. Guidelines for the initial management of head injuries. Recommendations from the Society of British Neurological Surgeons. Br J Neurosurg 1998;12:349-52.

13 The Royal College of Surgeons of England. Report of the Working Party on the management of patients with head injuries. London: The Royal College of Surgeons of London, 1999.

14 Phuenpathom N, Tiensuwan $M$, Ratanalert $S$, et al. The changing pattern of head injury in Thailand. J Clin Neurosci 2000;7:223-5.

15 Berney J, Favier J, Rilliet B. Head injuries in children: a chronicle of a quarter of a century. Childs Nerv Syst 1995;11:256-64.

16 Miller JD, Jones PA, Dearden NM, et al. Progress in the management of head injury. Br J Surg 1992;79:60-4. 